\title{
PERSAMAAN MEDAN DIRAC DALAM PENGARUH MEDAN MAGNETIK YANG SERAGAM
}

\author{
Oleh: \\ Andrias Widiantoro ${ }^{1}$, Erika Rani ${ }^{2}$
}

\begin{abstract}
ABSTRAK : Telah dilakukan perlakuan khusus terhadap persamaan gerak partikel elementer yaitu Persamaan Dirac dengan dipengaruhi oleh medan magnet eksternal yang seragam untuk mendapat solusi Persamaan Dirac dalam pengaruh medan magnetic. Penambahan pengaruh potensial magnetik terhadap momentum dan energi total suatu partikel bermuatan dalam kajian teoritis terhadap persamaan gerak yaitu persamaan Dirac telah memberikan solusi persamaan medan Dirac yang baru, dan kuantisasi kedua yang terdapat konstanta tambahan serta propagasi fermioniknya terdapat suku pengali baru.
\end{abstract}

Kata Kunci: Relativitas, Persamaan Dirac, Medan Magnetik.

\section{PENDAHULUAN}

Medan magnetik sering di temukan dalam berbagai skala kekuatan diseluruh jagat raya ini. Medan magnetik bumi ini mengelilingi bumi dan membentuk magnetosphere yang menyelubungi bumi yang disebut dengan selimut Van Allen (Van Allen Belt). Selimut medan magnet ini menghalau atau mencegah serbuan badai partikel elementer yang berasal dari reaksi inti bintang di alam raya yang tak terhingga jumlahnya.

Interaksi partikel elementer selalu menunjukkan hal - hal baru saat dikaji dalam background (latar belakang) yang tidak biasa. Studi propagasi partikel dalam suatu medan telah membuktikan bahwa terdapat hal - hal yang belum dimengerti pada permasalahan solar neutrino. Contoh yang khas dari permasalahan solar neutrino adalah hamburan neutrino-elektron (neutrino-electron scattering) dalam pengaruh suatu medium atau background. Neutrino yang telah dideteksi oleh detector di bumi hampir seratus persen berasal dari matahari.

Berdasarkan penelitan diketahui bahwa rata - rata energi total neutrino yang diterima oleh bumi tidak sebesar pada prediksi perhitungan. Hal ini menibulkan banyak dugaan, salah satunya adalah dugaan mengenai interaksi neutrino dengan medan magnetik bumi sebagai background tertentu. Dalam rangka untuk menentukan solusi baru yang lebih memadai bagi interaksi partikel dalam suatu background maka dilakukan perlakuan kusus terhadap persamaan geraknya yaitu persamaan Dirac. Dalam penelitian penelitan sebelumnya, persamaan Dirac hanya dikaji dalam ruang vakum (Erika Rani, 2004).

\footnotetext{
${ }^{1,2}$ Jurusan Fisika UIN Maliki Malang
}

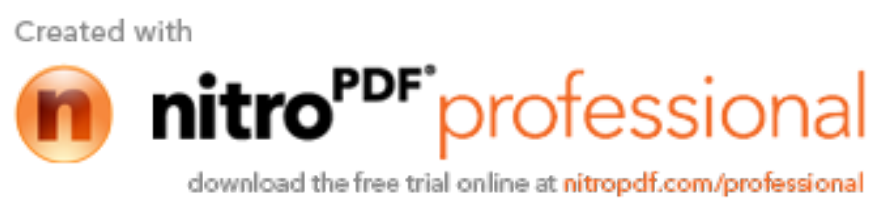


Persamaan Dirac adalah persamaan gerak yang menggambarkan seluruh tingkah laku partikel berspin setengah (partikel fermionik).

Oleh karena itu studi partikel elementer dalam pengaruh medan magnetik perlu dikembangkan sebagai salah satu upaya untuk menjawab berbagai permasalah yang muncul terkait partikel elementer. Penelitian partikel elementer dalam sebuah akselerator partikel juga menggunakan suatu medan untuk mempercepat dan mengarahkan partikel yang bertabrakan tersebut. Dalam penelitian ini akan dijabarkan persamaan medan Dirac yang menjadi persamaan gerak dari partikel elementer, dalam pengaruh medan magnetik. Medan magnetik dalam penelitian ini adalah medan magnetik yang seragam untuk memudahkan perhitungan.

\section{KAJIAN TEORI}

\section{PERSAMAAN DIRAC DALAM PENGARUH MEDAN MAGNETIK YANG SERAGAM}

Telah diketahui bahwa peralihan dari klasik ke kuantum dilakukan dengan merubah besaran momentum dan energi total menjadi suatu operator yang beroparasi pada suatu fungsi keadaan $\psi(x)$. Untuk partikel bermuatan listrik yang berada dalam ruangan bermedan magnetik, haruslah dilakukan penyesuaian. Diketahui bahwa medan magnetik adalah curl dari suatu potensial vekor

$$
B=\bar{\nabla} \times \bar{A}^{\alpha}(x)
$$

Dengan definsi dari potensial vektor dalam bentuk vektor empat

$$
\bar{A}^{\alpha}(x)=\left(c \Phi\left(x_{0}\right), \bar{A}(x)\right)
$$

Dengan demikian momentum dari suatu partikel bermuatan yang berada dalam pengaruh medan magnetik berubah menjadi

$$
P \rightarrow-i \hbar \bar{\nabla}+\frac{q}{c} \bar{A}^{\star}(x) \text { dengan } q \text { adalah muatan dari partikel tersebut }
$$

dan $c$ adalah kecepatan cahaya. Dengan demikian persamaan Dirac yang untuk partikel bermuatan listrik menjadi

$$
i \hbar \frac{\partial}{\partial t} \psi h(x)=\left(\sigma_{k}\left(-i \hbar c \bar{\nabla}+q A^{\alpha}(x)\right)+\beta m c^{2}\right) \psi h(x)
$$

Selanjutnya dari persamaan kuantum relativistik Dirac yang terpengaruh medan magnetik pada persamaan (4) dikalikan faktor $\beta / c$ dari ruas sebelah kiri, dan dengan sifat matriks Dirac pada persamaan (2.11), dan definisi matriks gama pada persamaan (2.10), serta menggunakan notasi yang didefinisikan pada persamaan (2.14) sehingga persamaan (4) dapat ditulis menjadi

$$
\left\{\hbar\left(\gamma_{\mu} \frac{\partial}{\partial x_{\mu}}\right)+i \frac{\gamma_{k}}{c} q \bar{A}^{\alpha}(x)+m c\right\} \psi(x)=0
$$

Persamaan (5) diatas adalah persamaan Dirac yang dipengaruhi oleh medan magnetik dengan $\gamma_{\mu}$ memenuhi hubungan antikomutasi. 
Selanjutnya dilakukan konjugat hermit pada persamaan Dirac diatas yang telah dipengaruhi medan magnetik. dengan menggunakan hubungan antikomutasi

$$
\gamma_{k} \gamma_{4}=-\gamma_{4} \gamma_{k}
$$

Sehingga persamaan (2.76) menjadi, maka persamaan Dirac dalam pengaruh medan magnetik menjadi

$$
\left\{\hbar \frac{\partial}{\partial x_{\mu}} \gamma_{\mu}-i \frac{\gamma_{k}}{c} q \bar{A}^{\alpha}(x)-m c\right\} \bar{\psi}(x)=0
$$

Persamaan diatas adalah persamaan Dirac Adjoin dalam pengaruh medan magnetik. Jika persamaan Dirac dan Persamaan Dirac Adjoin yang terpengaruh medan magnetik diatas dijumlahkan maka akan memenuhi persamaan kontinyuitas yang sama seperti persamaan Dirac pada partikel bebas.

\section{SOLUSI PERSAMAAN DIRAC DALAM PENGARUH MEDAN MAGNETIK YANG SERAGAM}

Solusi gelombang bidang untuk partikel dengan momentum $P$ dan energi $E$ adalah

$$
\psi(x)=U(P) \exp \left\{\frac{i}{\hbar}(P x)\right\}_{\text {dimana }} P=\left(P_{0}, P\right) \text { dan } x=\left(x_{0}, x\right) .
$$

Momentum $P_{0}=E_{F}$, pada $x_{0}=t$ yang merupakan ekspresi energi relativistik. Analisa satu persatu terhadap solusi persamaan gelombang yang di operasikan pada persamaan (5) yang merupakan persamaan Dirac yang terpengaruh medan magnetik sehingga

$$
\left\{-E_{F}-\sigma_{k}\left(-\boldsymbol{P} c+q A^{\alpha}(x)\right)-m c^{2} \beta\right\} U(P)\left(\exp \left\{\frac{i}{\hbar}(P x)\right\}\right)=0
$$

Fungsi eksponensial pada persamaan (9) diatas tidak mungkin bernilai nol, sehingga dapat ditulis menjadi

$$
\left\{-E_{p}+\sigma_{k}\left(\boldsymbol{P} c-q A^{\alpha}(\boldsymbol{x})\right)-m c^{2} \beta\right) U(\boldsymbol{P})-0
$$

Persamaan diatas adalah persamaan Dirac stasioner yang terpengaruh medan magnetik. Sama halnya dengan fungsi gelombang $\psi(x)$ maka $U(p)$ juga merupakan matrik kolom $(4 \times 1)$ dan dapat dibuat menjadi dua submatrik $(2 \times 1)$ yang disebut dua spinor.

$$
\left.u(P)-\left(\begin{array}{l}
u(P) \\
v(P)
\end{array}\right)-\left(\begin{array}{l}
u_{1}(P) \\
u_{2}(P)
\end{array}\right]\right)
$$

Dengan menggunakan definisi matrik Dirac pada persamaan (5) dan definisi pada persamaan (2.10), serta setelah dilakukan perhitungan rinci, sehingga persamaan Dirac Stasioner menjadi

$$
\left(\begin{array}{l}
E_{F} u(P) \\
E_{F} v(P)
\end{array}\right)=\left(\begin{array}{l}
\sigma_{i}\left(P c-q A^{\alpha}(x)\right) v(P) \\
\sigma_{i}\left(P c-q A^{\alpha}(x)\right) u(P)
\end{array}\right)+\left(\begin{array}{c}
m c^{2} u(P) \\
-m c^{2} v(P)
\end{array}\right)
$$


Dari persamaan (12) diatas dapat diuraikan berdasarkan masing - masing komponen matrik menjadi

$$
\left(E_{P}-m c^{2}\right) u(P)=\sigma_{i}\left(P c-q A^{\alpha}(x)\right) v(P)
$$

dan

$$
\left(E_{P}+m c^{2}\right) v(P)=\sigma_{i}\left(P c-q A^{\alpha}(x)\right) u(P)
$$

Selanjutnya persamaan (14) disubtitusikan kedalam persamaan (13) sehingga

$$
\left(E_{P}-m c^{2}\right) u(P)=\sigma_{i}\left(P c-q A^{\alpha}(x)\right) v(P)
$$

dengan definisi

$$
v(P)=\frac{\sigma_{i}\left(\boldsymbol{P}_{c}-q A^{\alpha}(x)\right) u(P)}{\left(E_{P}+m c^{2}\right)}
$$

sehingga persamaan (3.6B) menjadi

$$
\left(E_{P}-m c^{2}\right) u(P)=\frac{\left\{\sigma_{i}\left(P c-q A^{\alpha}(x)\right)\right\}^{2} u(P)}{\left(E_{P}+m c^{2}\right)}
$$

Setelah bagian kuadratik diuraikan, sehingga persamaan (15) menjadi

$$
\left(E_{F}^{2}-m^{2} c^{4}\right)-\left((\boldsymbol{P} c)^{2}-2 \boldsymbol{P} c \varphi A^{\sigma x}(x)+\left(q A^{\pi}(x)\right)^{2}\right) u(P)=0
$$

Karena $u(P)$ tidak mungkin nol, sehingga

$$
E_{p}^{2}=m^{2} c^{4}+(P c)^{2}+2 P c q A^{\alpha}(x)+\left(q A^{\alpha}(x)\right)^{2}
$$

Jika partikel dalam keadaan diam maka momentum dan vektor potensial menjadi nol sehingga

$$
E= \pm m c^{2}
$$

Hasil ini sesuai dengan ungkapan energi reltivistik saat partikel dalam keadaan diam. Karena persamaan Dirac dipenuhi dengan harga $E$, maka nilai tersebut merupakan nilai eigen dari Hamiltonian Dirac.

Spektrum energi partikel Dirac dapat diilustrasikan sebagai berikut :

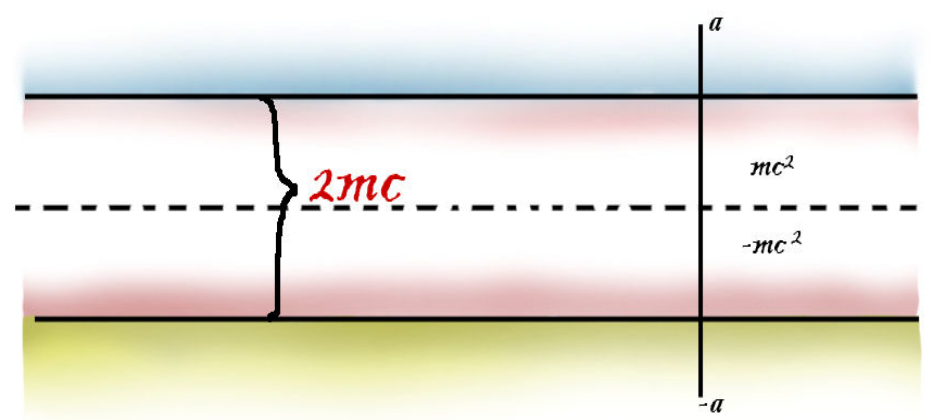

Gambar 1. Spektrum energi Dirac.

Gambar spectrum energi Dirac menggambarkan bahwa terdapat jarak atau rentang energi antara energi positif dan energi negatif dalam keadaan dasar dengan $P=0$. Sehingga dari energi negatif menuju energi positif diperlukan energi duakali energi dasar dan sebaliknya. 
Partikel Dirac bebas terdiri dari dua bagian yaitu bagian positif dan bagian negatif.

$>$ Bagian positif dimulai dari $E=m c^{2}$ ketika $P=0$ hingga positif takberhingga $+\alpha \cdot(|P| \rightarrow \infty)$.

Bagian negatif dimulai dari $E=-m c^{2}$ ketika $P=0$ hingga negatif takberhingga $-\alpha .(|P| \rightarrow-\infty)$

Diketahui bahwa ada jarak pemisah (Gap) energi dengan lebar $2 m c^{2}$ antara dua bagian energi.

$>$ Pada kondisi dasar, energi negative merupakan kebalikan dari energi positif sehingga jika energi postifif didefinisikan sebagai $E_{+}=E_{F}=m c^{2}$ maka enerfi negative didefinisikan $-E_{+}=-E_{p}=-m c^{2}$

Penerapan $U(P)$ untuk energi positif dan negatif dapat dijabarkan sebagai berikut:

Untuk energi negatif

$$
\left(-E_{+}-m c^{2}\right) u(P)=\sigma_{i}\left(P_{c}-q A^{\alpha}(x)\right) v(P)
$$

Dan untuk energi positif

$$
\left(E_{+}+m c^{2}\right) v(P)=\sigma_{i}\left(P c-q A^{n}(x)\right) u(P)
$$

Penjabaran untuk energi positif sebagai berikut,

$$
v(P)=\frac{\sigma_{i}\left(P_{c}-a A^{\alpha}(x)\right)}{\left(E_{+}+m c^{2}\right)} u(P)
$$

Uraian untuk bagian pembilang di ruas kanan pada persamaan diatas sebagai berikut :

$$
\sigma_{t}\left(P c-q A^{\alpha}(x)\right)=c \sigma_{t} P-q \sigma_{i} \bar{A}^{\alpha}(x)
$$

Dengan definisi matrik Dirac pada persamaan (2,10) dan $A^{\alpha}(x)$ adalah vektor potensial dalam bentuk vektor empat. Seperti yang telah didefinisikan pada persamaan (2). karena medan magnetik yang akan digunakan adalah medan magnetik yang seragam dan konstan maka diambil medan magnetik searah sumbu $z$, dengan vektor potensial adalah medan magnetik. Sehingga definisi vektor potensial pada persamaan(2)menjadi

$$
\begin{aligned}
\bar{A}^{\alpha}(x) & =\left(0,0,0, \bar{A}_{3}\left(x_{3}\right)\right) \\
& =B\left(x_{3}\right)
\end{aligned}
$$

Dengan $\Psi\left(x_{0}\right)=\bar{A}_{1}\left(x_{1}\right)=\bar{A}_{2}\left(x_{2}\right)=0$ dan $\bar{A}_{3}\left(x_{3}\right)=B$, dengan $B$ adalah medan magnetik konstan. Maka persamaan (90) menjadi

$$
\sigma_{i}\left(P_{c}-q \bar{A}^{\alpha}(x)\right)=\left(\begin{array}{cc}
c P_{5}-q B\left(x_{3}\right) & c\left(P_{1}-i P_{2}\right) \\
c\left(P_{1}+i F_{2}\right) & -c P_{3}+q B\left(x_{3}\right)
\end{array}\right)
$$

Jika persamaan persamaan (23) disubtitusikan kedalam persamaa persamaan (20) menjadi

$$
v(F)=\frac{1}{\left(E_{+}+m c^{2}\right)}\left(\begin{array}{cc}
c P_{3}-q B\left(x_{3}\right) & c\left(P_{1}-i P_{2}\right) \\
c\left(P_{1}+i P_{2}\right) & -c P_{3}+q B\left(x_{3}\right)
\end{array}\right) u(P)
$$

Diambil kemungkinan paling sederhana untuk sepinor $u(\mu)$, yaitu 
$u_{1}(P)=\left(\begin{array}{l}1 \\ 0\end{array}\right), \operatorname{dan} u_{2}(P)=\left(\begin{array}{l}0 \\ 1\end{array}\right)$

Dan untuk menyederhanakan

Spinor Dirac diatas, maka didefinisikan

$$
\begin{aligned}
& >P_{+}=P_{1}+i P_{2} \\
& >P_{-}=P_{1}-i P_{2}
\end{aligned}
$$

Sehingga untuk spinor - spinor Dirac didapat sebagai berikut:

1. Untuk spinor $u_{1}(P)$, dan didapat $U_{1}(P)$ yaitu :

$$
U_{1}(P)=N\left(\begin{array}{c}
1 \\
0 \\
\frac{c P_{3}-q B\left(x_{3}\right)}{\left(E_{+} \| m c^{2}\right)} \\
\frac{c P_{+}}{\left(E_{1}+m c^{2}\right)}
\end{array}\right)
$$

2. Untuk spinor $u_{2}(P)$ dan didapat $U_{2}(P)$ sebagai berikut :

$$
U_{2}(P)=N\left(\begin{array}{c}
0 \\
1 \\
\frac{c P_{-}}{\left(E_{+}+m c^{2}\right)} \\
\frac{-\left(c P_{3}-q B\left(x_{3}\right)\right)}{\left(E_{+}+m c^{2}\right)}
\end{array}\right)
$$

Dan dengan cara yang sama untuk energi negatif, maka didapat $V_{2}(P)$ dan $V_{2}(P)$ sebagai berikut

$$
\begin{aligned}
& \text { a. } \quad V_{1}(P)=N\left(\begin{array}{c}
\frac{-\left(c P_{3}-q B\left(x_{3}\right)\right)}{\left(E_{+}+m c^{2}\right)} \\
\frac{-c P_{+}}{\left(E_{+}+m c^{2}\right)} \\
1 \\
0
\end{array}\right) \\
& \text { b. } \quad V_{2}(P)=N\left(\begin{array}{c}
\frac{-c P_{-}}{\left(E_{+}+m c^{2}\right)} \\
\frac{c P_{3}-q B\left(x_{3}\right)}{\left(E_{+}+m c^{2}\right)} \\
0 \\
1
\end{array}\right)
\end{aligned}
$$

Dengan $N$ adalah konstanta normalisasi, Selanjutnya diketahui bahwa untuk mencari rapat peluang maksimum dari suatu fungsi gelombang adalah

$$
\begin{aligned}
|\psi(x)|^{2} & =1 \\
& =\psi^{*}(x) \psi(x)
\end{aligned}
$$

Dengan rapat peluang maksimum adalah satu $\left|U_{1}(P)\right|^{2}=1$ sehingga 29a dari persamaan (3.33), dapat diketahui konstanta normalisasi sebagai yaitu 


$$
N=\left(\frac{\left(E_{+}+m c^{2}\right)^{2}}{\left(E_{+}+m c^{2}\right)^{2}+c^{2} P^{2}-2 c q P_{3} B\left(x_{3}\right)+q^{2}\left(B\left(x_{3}\right)\right)^{2}}\right)^{\frac{1}{2}}
$$

Untuk $(P), V_{1}(P)$, dan $V_{2}(P)$ didapat hasil yang sama.

\section{KUANTISASI KEDUA DAN PROPAGASI FERMIONIK Kuantisasi Kedua}

Jika dilakukan operasi sekawan hermit pada persamaan Dirac yang tepengaruh medan magnetik, dan dengan menggunakan definisi konjugat hermit dan dilakukan perkalian dengan $\gamma_{4}$ dari ruas sebelah kanan, serta dengan menggunakan medan adjoint sehingga didapat

$$
\left\{\hbar \gamma_{\mu} \frac{\partial}{\partial x_{\mu}}-i \frac{\gamma_{k}}{c} q A^{\alpha}(x)+m c\right\} t b(x)=0
$$

Rapat Lagrangian yang memenuhi persamaan (31) dan persamaan (5) diberikan oleh

$$
L=c \bar{\psi}\left(r_{x} t\right)\left(\hbar \gamma_{\mu} \frac{\partial}{\partial x_{\mu}}+i \frac{\gamma_{k}}{c} q \bar{A}^{\alpha}(x)-m c\right) \psi(x)
$$

Dengan $\mathcal{L}_{0}$ adalah rapat lagranggian bebas

$\mathcal{L}_{0}=c \bar{\psi}(x)\left(\hbar \gamma_{\mu} \frac{\partial}{\partial x_{\mu}}-m c\right) \psi(x)$

dan $\mathcal{L}_{l}$ adalah rapat lagranggian interaksi

$\mathcal{L}_{I}=\bar{\psi}(x)\left(i \gamma_{k} q \bar{A}^{\alpha}(x)\right) \psi(x)$

Lagranggian interaksi menentukan semua variasi interaksi antara medan bebas dengan medan magnetik. Selanjutnya untuk mendapatkkan medan sekawan $\psi(r, t)$ dan $\bar{\psi}(r, t)$, didefinisikan medan skawan

$$
\pi(x)=\frac{\partial \mathcal{L}}{\partial \dot{\psi}(x)}, \operatorname{don} \bar{\pi}_{\alpha}(x)=\frac{\partial \mathcal{L}}{\partial \dot{\psi}(x)}
$$

Dengan menggunakan definisi rapat Lagranggian pada persamaan (32) sehingga medan sekawan untuk medan bebas $\psi(x)$ adalah

$$
\begin{aligned}
\pi(x) & =\frac{\partial \mathcal{L}}{\partial \psi(x)} \\
& =\operatorname{c\hbar } \bar{\psi}(x) \gamma_{4} \\
& =\hbar c \psi^{\dagger}(x)
\end{aligned}
$$

Persamaan diatas adalah medan sekawan bagi medan bebas $\psi(x)$.dan untuk medan sekawan bagi medan bebas adjoint $\bar{\psi}(x)$.

$$
\begin{aligned}
\bar{\pi}_{\alpha}(x) & =\frac{\partial \mathcal{L}}{\partial \frac{1}{\psi}(x)} \\
& =0
\end{aligned}
$$


Selanjutnya untuk mengkuantisasi medan Dirac maka medan bebas $\psi(x)$ harus diekpansi kedalam susunan lengkap yaitu

$$
\begin{aligned}
& \psi(x)-\sum_{r=}\left(\frac{1}{V D}\right)^{\frac{1}{2}}\left(a_{r}(P) U_{r}(P) e^{-\frac{i P_{x}}{\hbar}}+b_{r}^{\dagger}(P) V_{r}(P) e^{\frac{i P_{x}}{\hbar}}\right) \\
& \bar{\psi}(x)=\sum_{r p}\left(\frac{1}{V D}\right)^{\frac{1}{2}}\left(a_{r}^{\dagger}(P) \bar{U}_{r}(P) e^{\frac{i P_{x}}{\hbar}}+b_{r}(P) \bar{V}_{r}(P) e^{-\frac{i P_{x}}{\hbar}}\right)
\end{aligned}
$$

Dengan definisi

$$
D=\frac{\left(F_{+}+m c^{2}\right)^{2}+r^{2} \boldsymbol{P}^{2}-2 \pi r_{3} R\left(x_{\mathrm{g}}\right)+q^{2}\left(F\left(x_{\mathrm{g}}\right)\right)^{2}}{\left(E_{4}+m c^{2}\right)^{2}}
$$

Dari definisi - definisi diatas dapat ditarik hubungan antikomutasi antara medan bebas dengan medan sekawannya sebagai berikut :

$$
\begin{aligned}
& \left\{\psi(x), \pi\left(x^{\prime}\right)\right\}=\psi(x) \pi\left(x^{\prime}\right)+\pi\left(x^{\prime}\right) \psi(x) \\
& =2 \hbar=\delta_{\left(x-x^{\prime}\right)}
\end{aligned}
$$

Untuk hubungan antikomutasi antar medan bebas dan antar medan sekawannya memiliki

$$
\begin{aligned}
{[\psi(x), \psi(x)] } & =[\pi(x), \pi(x)] \\
& =0
\end{aligned}
$$

Selanjutnya didefinisikan suatu keadaan tanpa partikel dan lenyap jika dikenai oleh operasi anihilasi

$$
a_{r}(\boldsymbol{P}\rangle|0\rangle=0 \text {, wntuk semua } \boldsymbol{P}
$$

dan

$$
a_{r}^{\dagger}(\boldsymbol{P})|0\rangle=|1\rangle
$$

Atau dalam bentuk yang lebih umum, akan dilakukan operasi pada solusi persamaan Dirac dalam pengaruh medan magnetik terhadap ruang fock, sehingga Dengan definisi

$$
\begin{aligned}
& \psi(x)=\psi^{+}(x)+\psi^{-}(x) \\
& \psi^{+}(x)=\sum_{r P}\left(\frac{1}{V D}\right)^{\frac{1}{2}}\left(a_{r}(P) U_{r}(P) e^{-\frac{t F x}{\hbar}}\right) \\
& \psi^{-}(x)=\sum_{r P}\left(\frac{1}{V D}\right)^{\frac{1}{2}} b_{r}^{\dagger}(P) V_{r}(P) e^{\frac{i P_{x}}{\hbar}}
\end{aligned}
$$

Sehingga dari persamaan diatas diketahui bahwa

$$
\psi^{+}(x)|0\rangle=0
$$

Merupakan suatu operasi anihilasi atau pemusnahan partikel dan

$$
\psi^{-}(x)|0\rangle=|1\rangle
$$

Merupakan proses kreasi atau penciptaan partikel. Selanjutnya dilakukan

hal yang sama

untuk medan adjoint dan didapat

$\bar{\psi}^{-}(x)|0\rangle=|1\rangle$

merupakan suatu operasi kreasi atau penciptaan partikel dan reated with $_{\text {. }}$ 


$$
\bar{\psi}^{+}(x)|0\rangle=0
$$

merupakan proses anihilasi atau pemusnahan partikel.

\section{Propagator Fermionik}

Propagator Fermionik didefinisikan dengan

$$
\begin{aligned}
i S_{f}\left(x-x^{\prime}\right) & =\left\langle 0\left|\pi\left\{\psi(x) \bar{\psi}\left(x^{\prime}\right)\right\}\right| 0\right\rangle \\
& =\theta\left(t-t^{\prime}\right)\left\langle 0\left|\psi^{+}(x) \bar{\psi}^{-}\left(x^{\prime}\right)\right| 0\right\rangle-\partial\left(t^{\prime}-t\right)\left\langle 0\left|\bar{\psi}^{+}\left(x^{\prime}\right) \psi^{-}(x)\right| 0\right)
\end{aligned}
$$

Dengan menggunakan definisi pada persamaan (4.42) dan persamaan (4.46) dan dengan menggunakan persamaan Jordan lema sehingga didapat persamaan propagasi fermionik yaitu:

$$
\begin{aligned}
i S_{f}\left(x-x^{\prime}\right)= & \frac{1}{i(2 \pi)^{4}} \\
& \int \frac{2 c\left(m c^{2}+c \boldsymbol{P}\right)}{\left(E_{+}+m c^{2}\right)}\left\{\sum_{r=1}^{2} U_{r}(P) U_{r}(P)\right\} \frac{e^{\frac{i}{\hbar}\left(x-x^{2}\right)}}{P^{2}-m^{2}++i s} d^{4} P
\end{aligned}
$$

Persamaan diatas adalah propagator fermionik dalam pengaruh medan magnetik yang seragam yang dikenal dengan propagator dalam gambaran Fury. Untuk perhitungan rinci lihat Lampiran 3.7. Ada dua cara dalam menentukan propagator fermionik berdasarkan gambaran Fury. Pertama menentukan medan fermion yang merupakan solusi dari spinor Dirac dalam pengaruh medan magnetik yang seragam, selanjutnya menentukan operator kreasi dan anihilasi, serta membentuk suatu time order produck. Sehingga dari persamaan (4.64) diatas dapat diintepretasikan kedalam diagaram dalam gambar 2 sebagai berikut :

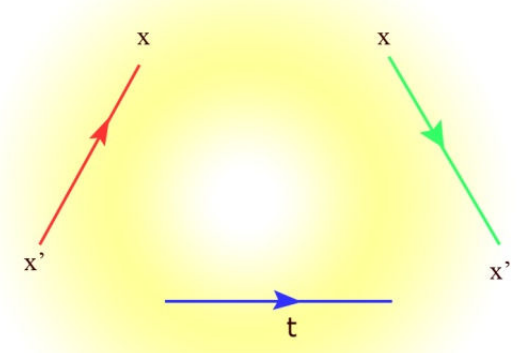

Gambar 2. Propagasi Fermionik

Dari gambar 2 diatas, untuk $t^{r}<t$ propagator Feynman memberikan interpretasi kreasi satu electron pada posisi $x^{z}$ kemudian berpropagasi ke posisi $x$, dan saat itu juga elektron teranihilasi (termusnahkan).

Sedangkan untuk $t^{\prime}>t$ positron terkreasi atau teremisi pada posisi $x$ kemudian berpropagasi ke $x^{\prime}$ dan pada saat itu juga positron teranihilasi (termusnahkan). Medan magnetik menyebabkan proses penciptaan dan pemusnahan partikel terjadi secara terus menerus dan simultan dalam tingkat sub atom, dan proses ini menyebabkan berubahnya 
rapat probabilitas dari partikel yang berinteraksi dengan medan magnetik tersebut. Hal tersebut terjadi setiap saat dan disetiap tempat serta seimbang.

\section{KESIMPULAN}

Solusi persamaan medan Dirac dalam pengaruh medan magnetik yang seragam menghasilkan sesuatu yang baru, yaitu terpengaruhnya momentum partikel oleh medan magnetik yang seragam searah sumbu $x_{3}$ atau $z$ sehingga didapat solusi persamaan Dirac yang berbeda dari solusi dalam keadaan vakum. Persamaan Dirac dalam pengaruh medan magnetik juga memenuhi kuantisasi kedua dengan konstanta tambahan $2 \hbar c$. Sedangkan propagasi fermionik dalam perngaruh medan magnetik dapat dibangun dengan dua langkah yaitu menentukan solusi dari persamaan medan Dirac dalam pengaruh medan magnetik yang seragam dan selanjutnya menentukan operator kreasi dan anihilasi serta membentuk suatu time order produck sesuai dengan gambaran Fury dan terdapat suku tambahan $\left(\frac{2 c\left(m e^{2}+c F\right)}{\left(E_{+}+m e^{2}\right)}\left[\sum_{r=1}^{2} U_{r}(P) \bar{U}_{r}(P)\right\}\right)$

\section{DAFTAR PUSTAKA}

Adikusumo. Filsafat Islam. http: //www.f-adikusumo. staff. ugm. ac. id/ artikel/ manusial/html. Diakses tanggal 28 Maret 2011.

A. D. Kaminker, O. Y. Gnedin, D. G. Yakovlev, P. Amsterdamski and P. Haensel,Phys. Rev. D 46, 4133 (1992).

A. D. Kaminker, K. P. Levenfish, D. G. Yakovlev, P. Amsterdamski and P. Haensel, Phys. Rev. D 46, 3256 (1992).

Alexander B Zamolodchikov. 2000. Factorized S-Matrices in Two Dimensions as The Exact Solution of Certain Relativistic Quantum Field Theory midels. Moscow, USSR: Institute of Theoretical and Experimental Physics.

Amir Hossein Sadeghi, Ali Naqavi, Sina Khorasani. Interaction of quantum dot molecules with multi-mode radiation fields. Tehran, Iran: School of Electrical Engineering, Sharif University of Technology.

A. Vidaurre, A. Perez, H. Sivak, J. Bernabeu and J. M. Iba nez, Astrophys. J. 448,264 (1995) [arXiv:astro-ph/9507027].

[9] Baltz.A.J. 1997. arXiv:physics/9701008v1 [physics.atom-ph] 10 Jan 1997 Exact Dirac equation calculation of ionization and pair production induced by ultrarelativistic heavy ions. Upton, New York 11973: Physics Department, Brookhaven National Laboratory. 
Bardensen dan Joachain. 2000. Quantum Mechanics. Edisi Kedua. Tottenham, England: Pearson prentice hall.

Bhattacharya,Kaushik. 2004. Elementary Particle Interactions in a Background Magnetic Field[arXiv:hep-ph/0407099v1 8 Jul 2004]. Kolkata, India: Jadavpur University.

Bhattacharya,Kaushik. 2010. Solution of the Dirac equation in presence of an uniform magnetic field[arXiv:0705.4275v2 [hep-th] 13 Aug 2007]. Mexico city, Mexico : Universidad Nacional Autonoma de Mexico.

David J. Griffiths. 1999. Introduction to electrodynamics. Upper suddle River, New Jersey: Reed Collage Prentive Hall.

Duane A. Dicus, Wayne W. Repko, and Todd M. Tinsley. 2010. arXiv:0704.1695v1 [hepph] 13 Apr 2007, Pair production with neutrinos in an intense background magnetic field. Austin, Texas 78712: Department of Physics, University of Texas at Austin.

George B Arfken dan Hans J weber. 2001. Mathematical Methods for Physicists, Fifth Edition. Oxford, Ohio Miami University and University of Virginia: A Harcourt Science and Technology Company.

Jean Francoid Burnol. 2003. arXiv:math/0302102v3 [math.NT] 10 Mar 2003, Dirac and Schrodinger Equation for The Fourier Transform. Lille, France: Universitas Lille 1, UFR de Matematiques.

John David Jackson. 2001. Classical Electrodynamics, Third Edition. Berkeley, university of California: Hamilton Printing Compani.

Purwanto, Agus. 2003. Fisika Matematika I dan II. Surabaya. Jurusan Fisika Fakultas Matematika dan Ilmu Pengetahuan Alam Institut Teknologi Sepuluh November (ITS).

Purwanto, Agus. 2006. Fisika Kuantum. Yogyakarta. Gava Media.

Rani, Erika. 2004. Medan Terkuantisasi dan Terapannya Dalam Hamburan Compton. Surabaya, Indonesia: Intitut Teknologi Sepuluh November.

S. J. Hardy and M. H. Thoma, Phys. Rev. D 63, 025014 (2001) [arXiv: astroph / 0008473].

Sunyoto, Agus. 2004. Suluk Sang pembaharu. Yogyakarta. Pustaka Sastra LKIS. 
Timothy Siahaan. 2004. Medan Klein-Gordon dan Medan Dirac Pada Ruang Minkowski Tak Komutatif. Yogyakarta,Indonesia: Universitas Gadjah Mada Fakultas Matematika dan Ilmu Pengetahuan Alam.

V.G.Bezchastnov and P. Haensel, Phys. Rev. D 54, 3706 (1996) [arXiv:astroph/9608090] 